\title{
The Application of Tennis Wall in Tennis Training and Analysis of Innovative Training Methods
}

\author{
Yadong Ren \\ (Huaiyin Normal University ,223300,Huai'an,Jiangsu,China) \\ jlryd@163.com
}

\section{Keywords: Tennis Training; Tennis Wall; Creative Training}

\begin{abstract}
With the rapid development of tennis in our country, more and more tennis enthusiasts participate in tennis. Tennis itself is a kind of sports project. It is not only conducive to physical fitness, leisure and entertainment, but also can win some honors for our country. However, due to the limited number of tennis courts, many people do not have the space to play. In order to be able to develop our country's tennis business more efficiently, we need to use tennis training and innovative training in tennis training. Under this realistic background, this paper, starting from the use of tennis wall, makes full use of the function of the tennis wall, constantly studies and summarizes the methods and functions of the practice of the wall ball, and combines the actual sports skills of tennis, in order to improve the students' tennis level constantly.
\end{abstract}

\section{Introduction}

Tennis and golf, bowling, and billiards are also known as the world's four major gentlemen's movements. They are known as tennis for the nobility. They were introduced to China by missionaries in the past and have now gone through nearly a hundred years. Nowadays, tennis is not only popular among nobles. With the development of many social factors such as the economy, education, culture, and politics in China, people's living standards have greatly improved and tennis has also begun to enter the public life. More and more people are playing tennis. Pick up a tennis racket, especially on the university campus. Compared with table tennis and badminton, tennis is a relatively late starter and its popularity is not high. It is not an advantage item in our country. However, in recent years, due to the outstanding achievements of the Women's Net in recent years, it has greatly inspired people's love of tennis. The development of tennis in China has shown a rapid development trend in the level of competition, popularity and scientific research. This article uses literature research methods, information research methods, mathematical statistics methods and other research methods. Through studying the problems existing in school tennis teaching and site construction at the present stage, the tennis wall is fully introduced into the teaching and training process of tennis. The role of tennis wall in teaching and training, the specific use methods, and the construction of tennis wall are summed up. And the specific ways of layout and what should be noted. I hope to provide some references for tennis teaching and training,and provide some references for the layout and construction of the auxiliary wall for tennis courts.

\section{Characteristics of Tennis Sports}

Tennis, as one of the world's most popular sporting events, has always been known as the "Aristocratic Movement," "Elegant Movement," and the Civilization Movement. At the same time, tennis is one of the most fashionable sports. Tennis is very different from table tennis and badminton. It has its own uniqueness.

Power. Between the top players of the world, in the men's competition, the athlete can send the fastest hour 240 kilometers of ball speed, equivalent to the speed of the car on the highway 2 times speed. Their average serve speed is also every hour 220 kilometers or so.Forehand shot can blast out every hour 180 kilometers of ball speed. Female athletes can also issue hourly Serve more than 200 kilometers. Strong arm and body strength are powerful guarantees for launching fastball. 
Sensitive. Tennis is the combination of strength and art. When we watch the game, we often see athletes make very exaggerated movements when they save the ball, such as crouching shots, frogs to save the ball, diving gymnastics to save the ball, roll back after the save and so on. The sensitive requirements of tennis for the body are also relatively high. Some people praised tennis as "sports ballet". The pace of tennis players is as light and graceful as those of ballet dancers.

Speed. The tennis court is large and the distance to hit the ball is far. In the course of the game, the athletes need to keep hitting the ball quickly, after the ball is hit, quickly return to the position to prepare for the next shot, and to make timely judgments. Relative to badminton and table tennis, the distance between them is far away, and the speed requirement for athletes is higher. If you move slowly, you will not be able to reach the hitting position, resulting in a failure to hit the ball.

Endurance. Someone once made statistics. In a fairly level tennis game, the distance the athletes run is about 5000 meters, some even reach 10,000 meters, no less than a fierce football game. In the course of a game, athletes must make timely judgments, advance or retreat from time to time, move left or right, jump or stop, and so on.

\section{The Problems in College Tennis Teaching}

The Form of Tennis Teaching in Colleges and Universities is Single. So far, many colleges and universities in China have set up tennis courses. However, because the actual teaching process has a relatively simple teaching format, teachers usually give a demonstration after explaining the theory first. However, due to lack of tennis training hours, With the shortage of tennis training venues, it is difficult for students to combine the knowledge taught by the teacher with the actual tennis training. Therefore, there is a general tendency that the level of student tennis is low.

The Lack of College Tennis Competitions. At present, there is only one tennis match among colleges and universities in China, which is the tennis competition for college students conducted every summer vacation. The development of this competition has, to a certain extent, expanded the influence of tennis, promoted the propaganda of tennis, and increased the enthusiasm of students to learn tennis. However, because tennis is a sport that has just emerged, compared with other types of sports, the development period is still short and the foundation for development is not yet solid. Like sports such as football and basketball, colleges and universities have a high number of competitions, some even once a week, but in addition to daily classroom training, tennis teaching has almost no form of intramural competition. To a certain extent, the enthusiasm of students for learning tennis has been weakened, which has seriously affected the progress of tennis teaching in the entire school.

\section{The Basic Requirements of the Tennis wall Training on the Venue Facilities}

What kind of facilities are suitable for tennis wall training? First of all, there is a wall for wall training, but the wall can be seen everywhere. Not all walls can be used for tennis practice. So what kind of wall can be a tennis wall? In the existing literature, there is no clear provision, and the general description is based on the practice experience or is only described under ideal conditions.

To build a tennis wall suitable for training, it must fully consider its use and use. At present, we can see that the tennis wall is only a subsidiary of the tennis court. Its main role is to assist in tennis training. This requirement for tennis walls should be considered from the venue, space and technical requirements of tennis.

Standard tennis court and space requirements, ground line 23.77 meters long; length of singles field line 8.23 meters, the length of the end of the doubles field 10.97 meters; outside the sideline 3.66 meters above 5.486 meters below obstacles, outside the bottom line6.4 meters above 6.4 meters below obstacles. The position of the tennis wall should be the nearest 3.66 meters or 6.4 meters of wire ends. For the height of the tennis wall, different opinions. How high should the wall be built? Ideally speaking, it can be said that the higher the better, but the construction of the site is to consider its cost, economic and practical is a realistic requirement. A complete tennis court should have screens on all four sides of the affiliated facilities, so the construction of a tennis wall 
should replace the role of the screen. In the national standard, the height requirement for the tennis court's nets must not be lower than 3.05 meters, then the tennis wall height requirement should not be lower than 3.05 meters. From the technical point of view, the height of 3.05 meters can also meet the height of the center of the tennis net. 0.914 meters, the height of the posts on both sides is 1.067 meters of practice requirements.

In terms of evenness, the tennis wall should also meet the corresponding national standard requirements as the tennis court. If the tennis wall is not smooth, the ball can easily bounce off the irregular wall during the practice and affect the training effect. Therefore, the flatness of the tennis wall should be up to the standard of the site plane.

\section{Tennis Training in the Use of Tennis Wall and Innovation}

The tennis wall itself has unique sports features and has an irreplaceable teaching role in tennis assisted exercises. Its own sports advantages include: the regularity of the rebound of the tennis wall against tennis, the problem of the serious shortage of tennis courts, the elimination of tennis practice partners, and the fact that they are not affected by natural weather. For example, rain and snow can also be used for tennis training on indoor walls.

Using the Tennis wall Practice ball Sense Method. Regardless of what form of ball sport people are playing, the key is to rely on the training of the so-called sense of the ball. It is also necessary for the students to find their own feelings through their constant efforts. Teachers need to let students find their own feeling of hitting the ball. For tennis beginners, the most difficult is not the tennis sports skills, but the timely and accurate judgment of the landing of the ball in tennis, the bouncing after landing, and the completion of technical movements throughout the process. This is the "ball" or "ball sensation" often mentioned by tennis players. This part of the teaching process is performed, in addition to teachers teaching students to exercise reasonable action, but also need to focus attention to students sense for the ball.

Coaches need to be constantly fed the ball in the teaching process, but also need to be and when practitioners judgment, experience footwork ability to play many times and can promptly identify the sweet spot. In this training activity, You can fully use the tennis wall to replace the work of teachers, but also from further adjustments to the wall or in front of the goal wall to hit a ball, changing methods of practice, and enhance training activities interesting, while also greatly increased The difficulty of training. In carrying out practical training, students can rely on the tennis wall a little closer, do not use the racket hitting the ground with the landing of the ball, repeatedly striking the ball as possible is not a mistake, and gradually develop students overall eyes, hands, feet, The mutual sense of coordination between rackets.

The Teacher Needs to Make Full Use of the Multi-ball Training Method in the Teaching Process. The current stage of the multi-ball training method, has become a tennis training activities in the most convenient and efficient method. Not only is it helpful for students to master tennis techniques and movements more fully, but it can also effectively train students' actual ball control abilities. Multi-ball training method, this teaching method for students, with a certain degree of difficulty, itself has a relatively strong challenge, but also further deepened the students' pressure tennis training. However, there will be pressure to be motivated. Multi-ball training will greatly consume students' physical strength and make students feel physically and mentally exhausted. In this way, teachers not only cultivate good student learning characters, but also further develop students' hardships. Hardworking learning spirit.

Transmitted simultaneously process more than the ball, the further test the students' ability to respond. Students face tennis from different directions and need to use different methods and actions to complete the ball-catching activities, further deepen their understanding and mastery of different tennis moves. Under this premise, the students, after patience and guidance from the teacher, thoroughly mastered the skills of tennis, and fully established a perfect tennis action circle that was completely his own personal characteristics. Multi-ball training methods, with more significant targeted, many learning difficulties are present in the continuous training process. Only in this way, students can accurately find their own learning deficiencies, and then continue to 
strengthen its play coherence. In addition, the multi-ball training method also has many forms, which can be a one-to-many form. It can also be a two-to-many model, or it can be a many-to-many form. Through the mutual cooperation of students in the class, not only can help students to completely correct their shortcomings, but also can further improve the students' tennis learning efficiency.

\section{Conclusion}

Today, with the prevalence of tennis, universities and colleges as the holy sites for spreading knowledge and training talents should take the brunt of increasing the training of tennis talents. In the course of daily tennis teaching, site factors and facilities conditions are the key factors influencing the quality of tennis teaching and learning interest of students. In order to enhance students' enthusiasm for learning as much as possible, in the actual teaching process, major universities and colleges must combine their own economic conditions, do their best to provide a good learning environment for tennis teaching, add related tennis facilities, establish tennis training grounds, and change the past. The venue fee system enhances students' interest in learning. At the same time, when teachers of colleges and universities teach tennis, they not only teach students the skills of striking tennis, but also teach students the relevant theory of tennis, so that students can combine theory with practice.

\section{References}

[1]Renò V, Mosca N, Nitti M, et al. Real-time tracking of a tennis ball by combining 3D data and domain knowledge[C]// International Conference on Technology and Innovation in Sports, Health and Wellbeing. IEEE, 2017:1-7.

[2] Yin Y. The innovation of college sports professional tennis teaching under the theory of multiple intelligences[J]. Journal of Chemical \& Pharmaceutical Research, 2014.

[3] Yang M L. Baseplate of Table Tennis Racket: Allocation for Material Innovation and Playing Methods[J]. Applied Mechanics \& Materials, 2014, 440:325-328.

[4] Gao M X, Liu H C. Innovation and Countermeasures of Jiangsu Athletic Tennis Reserve Personnel Training System[J]. Bulletin of Sport Science \& Technology, 2014.

[5] Li Z P. "Who is the Best Player of Table Tennis Champions" is the Innovation of National Fitness[C]// 3d International Conference on Applied Social Science Research. 2016.

[6] Gao B L, Faculty of P E, University Y. Study on the Characteristics, Structure and Technical Innovation of the Floor Wood of Table Tennis Racket[J]. Yinshan Academic Journal, 2017.

[7]Chae M. An innovative teaching approach to product development: creating tennis wear for female baby boomers[J]. Fashion \& Textiles, 2017, 4(1):13.

[8] Zhang X, Shang H. Rules of Using $40+$ Table Tennis Balls and Innovation Research on Techniques and Tactics of Table Tennis[J]. Bulletin of Sport Science \& Technology, 2015.

[9] Jiang J Q. The Innovation of the College Sports Specialty Tennis Teaching System Based on the Theory of Multivariate Intelligences[J]. Applied Mechanics \& Materials, 2014, 644-650:6031-6034.

[10] Liu M. Research on the Development Situation and Innovation Approaches of Table Tennis Coaches[J]. Bulletin of Sport Science \& Technology, 2017.

[11]Luitzen J, Bollerman T, Delheye P. Playing on the Field of Social and Technical Innovation: The Impact of the Sale of Lawn Tennis Sets in the Netherlands, 1874-1887[J]. International Journal of the History of Sport, 2015, 32(9):1181-1204.

[12]Chae M. An innovative teaching approach to product development: creating tennis wear for female baby boomers[J]. Fashion \& Textiles, 2017, 4(1):13.

[13] Gao B L, Faculty of P E, University Y. Study on the Characteristics, Structure and Technical Innovation of the Floor Wood of Table Tennis Racket[J]. Yinshan Academic Journal, 2017.

[14] Chen C. The Influence of Training Methods' Innovation on Promoting Competitive Ability of Tennis Athletes _ A Case Study of the National Soft Tennis Team[J]. Journal of Lanzhou University of Arts \& Science, 2018. 